\title{
Impact of dietary phosphorus on turbot bone mineral density and content
}

\author{
Paula Suarez-Bregua $^{1}$ ( ) Rogerio P. Pirraco ${ }^{2,3}$ | Jorge Hernández-Urcera ${ }^{4,6}$ | \\ Rui L. Reis ${ }^{2,3,5}$ | Josep Rotllant ${ }^{1}$
}

${ }^{1}$ Department of Biotechnology and Aquaculture, Institute of Marine Research (IIM-CSIC), Vigo, Spain

23B's Research Group-Biomaterials, Biodegradables, and Biomimetics, Headquarters of the European Institute of Excellence on Tissue Engineering and Regenerative Medicine, University of Minho, Guimarães, Portugal

${ }^{3}$ ICVS/3B's - PT Government Associate Laboratory, Braga/Guimarães, Portugal

${ }^{4}$ Oceanographic Center of Vigo, Spanish Institute of Oceanography (IEO), Vigo, Spain

${ }^{5}$ The Discoveries Centre for Regenerative and Precision Medicine, Headquarters at University of Minho, Guimarães, Portugal

${ }^{6}$ Department of Ecology and Marine Resources, Institute of Marine Research (IIM-CSIC), Vigo, Spain

\section{Correspondence}

Paula Suarez-Bregua and Josep Rotllant, Department of Biotechnology and

Aquaculture, Institute of Marine Research (IIM-CSIC), Vigo, Spain.

Emails: paulasuarez@iim.csic.es (PS-B); rotllant@iim.csic.es (JR)

Funding information

Spanish Economy and Competitiveness Ministry project, Grant/Award Number: AGL2014-52473R and AGL2017-89648P

\begin{abstract}
Fish are largely dependent on dietary phosphorus for skeletal development and mineralization. In aquaculture, commercial diets commonly have higher phosphorus concentration than the basal requirements in most fish species to ensure growth and prevent bone mineral disorders. Excessive phosphorus in feeds is harmful for metabolism and results in an increase of wastes in farm effluents, which impact aquatic ecosystems. Previous studies have shown that depletion/excess of dietary phosphorus cause skeletal malformations and reduced/enhanced mineralization in fish. There is scarce information on dietary phosphorus requirements for optimal bone mineralization in species with different types of bone (cellular vs. acellular bone), which is particularly relevant for sustainable aquaculture. Thus, the aim of our study was to analyse the effect of dietary phosphorus concentrations on bone mineralization of turbot, a demersal acellular-boned fish and valuable aquaculture species. Our results show that the dietary phosphorus concentration did not cause changes to the bone mineral density and the phosphate/calcium concentrations. No apparent skeletal malformations were detected. Additionally, we did not find an altered expression of genes involved in bone mineral metabolism. Taken together, our data show that the phosphorus requirements for optimum growth and bone mineralization in turbot are below those currently used commercially at least for the time period examined: 55-195 days postfertilization (dpf).
\end{abstract}

\section{KEYWORDS}

acellular bone, bone mineralization, dietary phosphorus, growth, skeletal physiology, turbot

\section{1 | INTRODUCTION}

Phosphorus is an essential nutrient for skeletal physiology, ionic homeostasis and energy metabolism in fish. Unlike other minerals, the phosphorus content in water is insufficient to meet fish requirements and therefore the diet is the main external source of phosphorus (Lall, 2002; Lall \& Lewis-McCrea, 2007). In aquaculture, the use of balanced phosphorus diets based on specific fish requirements is crucial to prevent bone mineral disorders and environmental pollution. Currently, there is particular concern with regard to excess phosphorus in waste outputs from fish farming. Excess phosphorus in water from uneaten food and urinary/faecal excretions produces eutrophication of aquatic ecosystems, which is becoming a serious environmental problem (Cho \& Bureau, 2001; Correll, 1998; Hixson, 2014). Additionally, competition of the use of phosphate in other industries (agricultural (fertilizers, etc.), non-agricultural (food sector (additives, etc.) and household products (detergents, cleansers, etc.) and its characteristic as a 
finite, irreplaceable, nonrenewable resource has enormously increased its market price and therefore also the need to reduce its use (Daneshgar et al., 2018).

In all vertebrates, most of the whole-body phosphorus absorbed is present as inorganic phosphate $\left(P_{i}\right)$ and crystallizes along with calcium and other micronutrients to form hydroxyapatite (HA), which hardens the extracellular bone matrix and acts as an internal mineral store (Bonjour, 2011; Kini \& Nandeesh, 2012). If required, bone minerals provide a rapid exchange of $P_{i}$ and calcium ions between the skeleton and blood through a process called bone remodelling (Lall \& Lewis-McCrea, 2007; P Eckhard Witten \& Huysseune, 2009). Thus, bone remodelling contributes to $P_{i}$ and calcium release from bone by bone resorption and mineral deposition on bone through bone formation (Sims \& Gooi, 2008). Diverse studies have described that deficiency of dietary phosphorus produces reduced bone mineralization, diverse skeletal deformities and poor growth performance in different farmed fish species including Atlantic salmon (Salmo salar) (Baeverfjord et al., 1998; Fjelldal et al., 2016; Witten et al., 2016), rainbow trout (Oncorhynchus mykiss) (Le Luyer et al., 2014), common carp (Cyprinus carpio) (Ogino \& Takeda, 1976), zebrafish (Danio rerio) (Costa et al., 2018), Atlantic halibut (Hippoglossus hippoglossus) (Lewis-McCrea \& Lall, 2010) and haddock (Melanogrammus aeglefinus L.) (Roy et al., 2002). On the other hand, excess phosphorus in feeds has been shown to cause enhanced skeletal mineralization and an increase of $\mathrm{P}_{\mathrm{i}}$ excretion in juvenile haddock (Roy \& Lall, 2003; Roy et al., 2002). Despite the relationship reported between low or high dietary phosphorus levels and bone mineral disorders, the involvement of fish bone type and their dietary phosphorus requirements for optimal mineralization together with the speciesspecific behaviour and traits have been overlooked. Currently, it is well known that not all teleost fish species have the same type of bone. Most teleosts, including salmonids and cyprinids, have a cellular bone with osteocytes in the bone matrix, whereas species belonging to perciformes, pleuronectiformes, or gadiformes orders, which represent at least $50 \%$ of the bony vertebrate species, have bone that does not contain osteocytes, termed acellular bone (Shahar \& Dean, 2013; Witten \& Huysseune, 2009). So, the existence of fish with anosteocytic (acellular) bone raises a fascinating question of how the skeleton of these animals performs the different fundamental functions attributed to osteocytes in other vertebrates.

Turbot (Scophthalmus maximus) is an important aquaculture demersal fish species. High-phosphorus-based commercial diets have commonly been used for turbot culture under intensive conditions (Mallekh et al., 1999). However, long-term sustainable fish farming requires reducing the phosphorus levels in feeds to provide for turbot requirements without affecting growth performance, health and welfare. Additionally, it should also be noted that the shift in aquaculture from marine ingredients rich in phosphorus (like fish meal) to alternative ingredients of plant origin which tend to contain phosphorus in unavailable source stored as phytate (Sugiura et al., 2001) implies the need to be added to the diet and therefore the need to know precisely the phosphorus requirements of each particular species.

\section{2 | MATERIAL AND METHODS}

\subsection{Fish}

Turbot were reared at the facilities of the Centro Oceanográfico de Vigo (Spain) according to standard procedures used for this species (Torres-Núñez et al., 2015). Fish were kept at ambient temperature $\left(18 \pm 1^{\circ} \mathrm{C}\right)$ and constant photoperiod (12-h light/12-h dark). Water quality was monitored daily. Larvae were staged according to AlMaghazachi and Gibson (1984). Ethical approval (Ref.: AGL201452473R and AGL2017-89648P) for all studies was obtained from the Institutional Animal Care and Use Committee of the IIM-CSIC Institute in accordance with the National Advisory Committee for Laboratory Animal Research Guidelines licensed by the Spanish Authority (RD53/2013) and conformed to the European animal directive (2010/63/UE) for the protection of experimental animals.

\section{2 | Feeding experiments and sampling}

Four hundred turbot (55 days postfertilization (dpf); $0.73 \pm 0.17 \mathrm{~g}$ mean wet weight) were randomly distributed in six $450-\mathrm{L}$ flatbottomed fibreglass tanks (around 65 fish per tank) connected to an open seawater system. The volume of the tanks during the experiment was kept at about $250 \mathrm{~L}$. The water turnover rate was adjusted to about $12 \mathrm{~L} / \mathrm{min}$. Fish from duplicate tanks were fed to apparent satiation three times a day with one of the three experimental diets: low-phosphorus diet (LP, 0.47\%), standard-phosphorus diet (SP, 1.30\%) and high-phosphorus diet (HP, 3.15\%; Table 1). The experimental diets were designed and formulated by Sparos Ltd. Company. Inclusion levels of calcium carbonate and sodium chloride were adjusted among the diets in order to keep $\mathrm{Ca}$ and $\mathrm{Na}$ constant and therefore isolate phosphorus as the main variable mineral. Dietary trials were conducted for 20 weeks. After this period, $195 \mathrm{dpf}$ turbot were randomly sampled, euthanized by using MS-222 (Sigma), weight and length measurements were recorded, and fixed for subsequent analysis.

\section{3 | Micro-computed tomography (CT) scanning and whole-body mineral contents analysis}

Volumetric bone mineral density (vBMD) was determined in turbot ( $n=30 ; 10$ per group) according to the guidelines set up by Hur et al. (2017). In our study, it is shown that a resolution of $21 \mu \mathrm{m}$ has enough sensitivity to discern variations in the $\mathrm{VBMD}$ of individual vertebrae related to abnormal phenotypes in fish. Fish were euthanized and fixed in $2 \%$ paraformaldehyde (PFA) at $4^{\circ} \mathrm{C}$ and scanned with a vivaCT 80 (Scanco Medical). Scanning was performed at $55 \mathrm{kVp}$ X-ray 
TABLE 1 Feed composition and formulation of the lowphosphorus (LP), standard-phosphorus (SP), and high-phosphorus (HP) diets

\begin{tabular}{|c|c|c|c|}
\hline & LP & SP & HP \\
\hline \multicolumn{4}{|l|}{ Ingredients $\left(\mathrm{g} \mathrm{kg}^{-1}\right.$ ) } \\
\hline Fish gelatin & 75.0 & 75.0 & 75.0 \\
\hline Casein & 200.0 & 200.0 & 200.0 \\
\hline Casein hydrolysate & 87.0 & 87.0 & 87.0 \\
\hline Wheat Gluten & 100.0 & 100.0 & 100.0 \\
\hline Dextrine & 150.0 & 150.0 & 151.0 \\
\hline Cellulose & 66.0 & 45.5 & 0.0 \\
\hline Fish oil & 150.0 & 150.0 & 150.0 \\
\hline Vit \& Min Premix PV02 & 2.0 & 2.0 & 2.0 \\
\hline Lutavit C35 & 2.0 & 2.0 & 2.0 \\
\hline Lutavit E50 & 0.5 & 0.5 & 0.5 \\
\hline Choline chloride & 5.0 & 5.0 & 5.0 \\
\hline Betaine $\mathrm{HCl}$ & 5.0 & 5.0 & 5.0 \\
\hline Soy lecithin & 20.0 & 20.0 & 20.0 \\
\hline Binder (guar gum) & 10.0 & 10.0 & 10.0 \\
\hline $\begin{array}{l}\text { Antioxidant powder } \\
\text { (Paramega PX } \\
\text { KEMIN) }\end{array}$ & 4.0 & 4.0 & 4.0 \\
\hline $\begin{array}{l}\text { Antioxidant liquid } \\
\text { (Paramega PX' } \\
\text { KEMIN) }\end{array}$ & 1.0 & 1.0 & 1.0 \\
\hline Sodium propionate & 2.0 & 2.0 & 2.0 \\
\hline $\begin{array}{l}\text { Monocalcium } \\
\text { phosphate }\end{array}$ & 12.0 & 50.0 & 110.0 \\
\hline $\mathrm{NaH} 2 \mathrm{PO} 4$ & 0.0 & 0.0 & 21.0 \\
\hline $\mathrm{NaCl}$ & 10.0 & 10.0 & 0.0 \\
\hline Ca carbonate & 44.0 & 26.5 & 0.0 \\
\hline L-Arginine & 2.0 & 2.0 & 2.0 \\
\hline L-Threonine & 5.0 & 5.0 & 5.0 \\
\hline L-Tryptophan & 3.5 & 3.5 & 3.5 \\
\hline DL-Methionine & 9.0 & 9.0 & 9.0 \\
\hline L-Taurine & 5.0 & 5.0 & 5.0 \\
\hline Glycerol & 20.0 & 20.0 & 20.0 \\
\hline Sorbitol & 10.0 & 10.0 & 10.0 \\
\hline \multicolumn{4}{|l|}{ As fed basis $\left(\mathrm{g} \mathrm{kg}^{-1}\right)$} \\
\hline Total P & 4.7 & 13.0 & 31.5 \\
\hline Crude fat & 169.2 & 169.2 & 169.2 \\
\hline Ash & 56.9 & 52.5 & 50.0 \\
\hline Gross energy (MJ kg ${ }^{-1}$ ) & 19.54 & 19.25 & 18.62 \\
\hline $\mathrm{Ca}$ & 21.9 & 21.9 & 22.3 \\
\hline $\mathrm{Na}$ & 4.1 & 4.1 & 4.2 \\
\hline
\end{tabular}

source voltage and $145 \mu \mathrm{A}$ source current with an integration time of $330 \mathrm{~ms}$ and voxel size of $20.8 \mu \mathrm{m}$. Image projections were reconstructed with Scanco Medical software suite (Scanco Medical) after segmentation using values of 293.5 (mg of Hydroxyapatite per cubic centimetre).

In the scanned area, two different volumes of interest (VOIs) were selected: skull (i.e. dermal bone) and vertebra (i.e. endochondral bone). Skull (VOI1) includes the portion of the head between the lapilli and sagittal otoliths and VOI2 includes the fifth vertebra from the postcranial region of the spine. VBMD in each VOI was expressed as milligrams of HA per cubic centimetre.

For whole-body calcium and phosphorus determination, fish ( $n=10$ per group) were euthanized and frozen at $-20^{\circ} \mathrm{C}$. Fish were freeze-dried until dry (dry weight) and dissolved in concentrated nitric acid (70\%; $3 \mathrm{ml} \mathrm{g}^{-1}$ dry weight; Sigma-Aldrich). Nitric acid sample digestions were diluted 500 -fold with demineralized water and analysed for calcium and phosphorus by using inductively coupled plasma optical emission spectrophotometry (Optima 4300DV ICPOES; Perkin Elmer). Mineral content was expressed in milligrams per gram dry body weight, based on the fish dry weight and the total sample digestion volume.

\subsection{Quantitative real-time polymerase chain reaction (qPCR)}

For quantitative real-time PCR (qPCR) analysis, fish ( $n=10$ per group) were fixed in RNAlater ${ }^{\mathrm{TM}}$ (Invitrogen) and stored at $-80^{\circ} \mathrm{C}$. Then, specimens were dissected to extract the brain and spine. The total RNA from tissues was isolated by using RNeasy Mini Kit (Qiagen) and 200 ng of the RNA was reverse-transcribed according to the Maxima First Strand cDNA Synthesis Kit (Thermo Fisher Scientific) protocol. Samples were amplified in triplicate containing $12.5 \mu \mathrm{l}$ of Maxima SYBR Green/ROX qPCR Master Mix (2X) (Thermo Fisher Scientific), $0.5 \mu \mathrm{l}$ of $0.2 \mu \mathrm{M}$ of each primer, $10.5 \mu \mathrm{l}$ nuclease-free water and $1 \mu \mathrm{l}$ of cDNA template. qRT-PCRs were analysed with a QuantStudio3 Real-Time PCR System (Thermo Fisher Scientific) with the following cycling conditions: initial denaturation at $95^{\circ} \mathrm{C}$ for $10 \mathrm{~min}$ followed by 40 cycles at $95^{\circ} \mathrm{C}$ for $15 \mathrm{~s}$ and $60^{\circ} \mathrm{C}$ for $1 \mathrm{~min}$. Expression of bone mineralization and $\mathrm{P}_{\mathrm{i}}$ homeostasis markers was assessed by using the efficiency calibrated method as previously described (Pfaffl, 2001). Relative mRNA expression levels in the brain and spine were normalized to the housekeeping 185 ribosomal gene. Primer sets used for each gene are listed in Table 2.

\subsection{Statistics}

Data were expressed as mean \pm standard error of the mean (SEM). Differences between the two groups were assessed by Student's $t$ test. Multiple comparisons between numerical data were evaluated by one-way ANOVA with Tukey's post hoc test. Statistical analyses and figures were performed with $\mathrm{R}$ Studio ( $\mathrm{R}$ statistical software v3.3.2) and SigmaPlot 12.0. 


\begin{tabular}{lll}
\hline Turbot genes & Forward primer sequence (5'-3') & Reverse primer sequence (5'-3') \\
\hline pth4 (XP_035486518) & ATGCAGACGATGTCCCACAG & CAGCACCTTTGTGGGGTTGAA \\
sparc(XM_035650021) & TGAACCACCACTGCAAGAAG & TCAGATGACGAGGTCTTTGTCCA \\
entpd5 (XP_035465670) & TGTGCAACAAAATGACCAAA & GTTGTCCTTGAAGCCAAAGC \\
18S (XR_004790016) & GACTCAACACGGAAACCTC & AACCAGACAAATCGCTCCAC \\
\hline
\end{tabular}

TABLE 2 Primer sequences used for quantitative RT-PCR gene expression analysis

\section{$3 \mid$ RESULTS}

\section{1 | Fish growth}

The effect of dietary phosphorus on fish growth is shown in Table 3. Turbot significantly increased in body length and weight, and no external signs of deformities were observed. Turbot fed LP, SP and HP diets showed around 54\% length increase and $89 \%$ weight increase in all experimental diets, and no significant differences were found in size or condition factor between experimental diets (Table 3).

\section{2 | Bone mineral density and changes in whole- body mineral contents}

To investigate whether dietary phosphorus contents could differentially affect bone mineral accrual in turbot an acellular-boned fish species, we analysed the volumetric bone mineral density (vBMD) by micro-CT scanning (Figure 1). We determined the VBMD in two different types of bones according to their cellular origin: skull, which is formed from mesenchymal cells by intramembranous ossification, and vertebral bone (i.e. spine), which is derived from a cartilage template and develops by endochondral ossification. In turbot, no significant differences were detected in VBMD of the skull (LP, $704.25 \pm 21.56$; SP, $712.52 \pm$ 13.16; HP, $728.59 \pm$ 13.67; Figure 1a) and vertebrae samples (LP, $636.62 \pm 22.62$; SP, $667.09 \pm 21.22$; HP, $705.25 \pm 10.64$; Figure 1b) for the three diets used.

To corroborate the $\mathrm{VBMD}$ results, we analysed how the dietary phosphorus content affects whole-body phosphorus and calcium concentrations by using ICP-OES analysis. Whole-body mineral concentrations showed no significant differences in phosphorus and calcium levels of turbot fed the LP (P, $12.86 \pm 0.85$; Ca, $24.66 \pm 1.53)$

TABLE 3 Growth measurements of turbot fed low-phosphorus (LP), standard-phosphorus (SP) and high-phosphorus (HP) diets for 20 weeks

\begin{tabular}{|c|c|c|c|}
\hline Turbot & LP & SP & HP \\
\hline $\begin{array}{l}\text { Length } \\
\quad \text { increase (\%) }\end{array}$ & $54.04 \pm 0.72^{\mathrm{a}}$ & $54.48 \pm 0.77^{a}$ & $53.25 \pm 0.97^{a}$ \\
\hline $\begin{array}{l}\text { Weight } \\
\quad \text { increase (\%) }\end{array}$ & $89.35 \pm 0.55^{a}$ & $89.89 \pm 0.57^{a}$ & $88.26 \pm 1.03^{a}$ \\
\hline $\begin{array}{l}\text { Condition } \\
\text { factor (K) }\end{array}$ & $1.57 \pm 0.04^{a}$ & $1.61 \pm 0.05^{\mathrm{a}}$ & $1.53 \pm 0.05^{a}$ \\
\hline
\end{tabular}

Data are presented as means \pm SEM ( $n=30$ per group).

Different lower-case letters denote significant differences (one-way ANOVA).
$\mathrm{SP}(\mathrm{P}, 15.58 \pm 1.04 ; \mathrm{Ca}, 29.35 \pm 2.03)$ and HP diets $(\mathrm{P}, 14.65 \pm 1.23$; Ca, $27.17 \pm 2.47$; Figure 2a,b).

\section{3 | Bone mineral homeostasis markers}

We next asked whether dietary phosphorus concentration could affect expression of the genes involved in bone mineral homeostasis of turbot. So, by using qRT-PCR, we analysed the expression levels of bone mineralization and $\mathrm{P}_{\mathrm{i}}$ homeostasis markers, including parathyroid hormone 4 (pth4), a systemic factor that controls phosphate homeostasis via regulation of bone mineral content (Suarez-Bregua et al., 2017), osteonectin (sparc), a marker of the osteoblastic functional differentiation of bone cells (Li et al., 2009), and ectonucleoside triphosphate/diphosphohydrolase 5, a key phosphaturic factor that acts in the intestine to adjust phosphate absorption (entpd5) (Huitema et al., 2012). The dietary treatments did not influence gene expression levels of pth4, sparc and entpd5 in turbot (Figure 3).

\section{4 | DISCUSSION}

Phosphorus, in the form of $\mathrm{P}_{\mathrm{i}}$ (inorganic phosphate), is an essential macronutrient in vertebrates, including fish. In fish, the main route for $P_{i}$ entry is through the diet (Lall, 2002). Any excess of $P_{i}$ in the diet above the minimum requirement for fish will be excreted. So, the excess of unused/excreted inorganic phosphate (phosphorus products) by fish is the origin of most dissolved inorganic waste resulting from intensive fish farming (Dauda et al., 2019). The excess of this element in the effluents of aquaculture systems leads to eutrophication and a consequent change in the aquatic ecosystem (Cho \& Bureau, 2001; Correll, 1998; Jahan et al., 2000; Lazzari \& Baldisserotto, 2008). It is therefore critical to know precisely the dietary requirement of $\mathrm{P}_{\mathrm{i}}$ in order to minimize excess phosphorus in fish diets without risking phosphorus deficiency in cultured fish. Here, we examined the effect of dietary phosphorus (i.e. $0.47 \%, 1.30 \%$ and $3.15 \%$ total phosphorus in the diet, named as LP, SP and HP diets, respectively) on the growth and bone mineral homeostasis in turbot, a fish species with acellular bone structure. Our results show that bone mineral density was not affected in turbot and dietary phosphorus did not significantly influence the growth performance. It has already been shown that growth is not always affected by dietary phosphorus (Chaimongkol \& Boonyaratpalin, 2001; Luo et al., 2009). In this study, therefore, it seems that the LP diet $(0.47 \%)$ has a suitable amount of phosphorus to meet the physiological needs of 

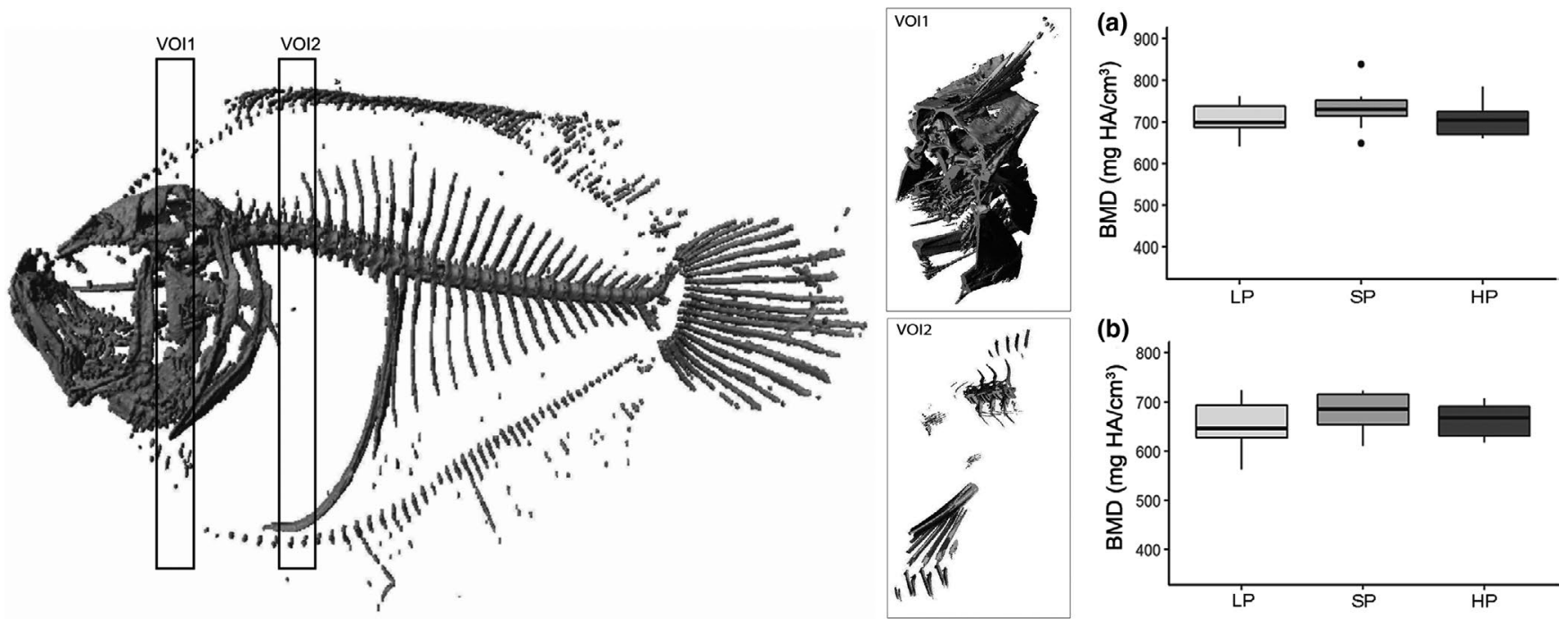

FIGURE 1 Volumetric bone mineral density (VBMD) analysis of turbot fed LP, SP and HP diets. Three-dimensional (3D) reconstruction from micro-CT scans of turbot skeleton. Two volumes of interest (VOIs) were selected for vBMD determination: skull (VOI1, including a portion of the head between the lapilli and sagittal otoliths) and vertebra (VOI2 is a single vertebra from the spine). (a, b) Box plots representing the VBMD measurements $\left(\mathrm{mg} \mathrm{HA} \mathrm{cm}^{-3}\right.$ ) performed for turbot ( $\mathrm{a}$, skull; b, vertebra) under different dietary phosphorus contents. Boxes depict the interquartile range, and the black line represents median. Whiskers show the minimum and maximum data, and black circles are considered as outliers

FIGURE 2 Whole-body phosphorus and calcium concentration determination in turbot $(a, b)$ fed LP, SP and HP diets
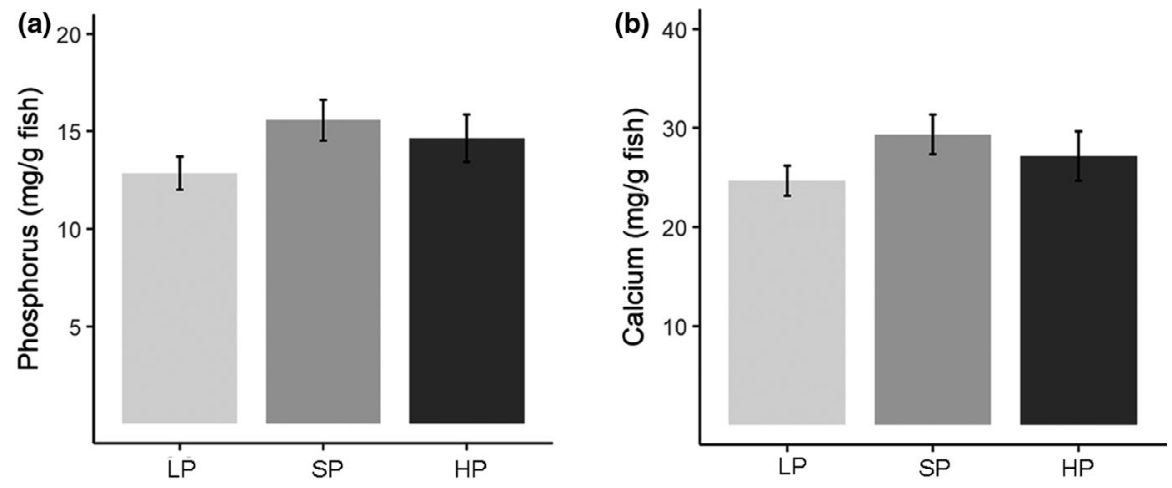

growth and well-being as well as to prevent any skeletal signs of this nutrient's deficiency in turbot.

Bone mineralization is an essential physiological process for proper skeletal metabolism and welfare in fish species. Absorbed $\mathrm{P}_{\mathrm{i}}$ mineralizes along with calcium to confer the stiffness and strength that bone needs, which in turn is directly related to the whole-body mineral content. Moreover, deposited calcium phosphate makes the skeleton an efficient mineral reservoir for storage or removal of ions through bone formation or resorption, respectively (Kini \& Nandeesh, 2012; Witten \& Huysseune, 2009). Previous studies have shown that phosphorus deficiency (dietary phosphorus levels lower than $0.35 \%$ ) causes low bone mineralization and is responsible for numerous skeletal malformations in cellular-boned fish species (Baeverfjord et al., 1998; Costa et al., 2018; Fjelldal et al., 2016; Le Luyer et al., 2014; Ogino \& Takeda, 1976; Witten et al., 2016). On the other hand, excess $\mathrm{P}_{\mathrm{i}}$ has deleterious consequences, leading to endocrine and renal dysfunction, ectopic calcification and eventually death (Sugiura et al., 2004; Vielma \& Lall, 1998), being between 1\% and $1.7 \%$ dietary phosphorus levels the standard concentration used in most of the fish species studied.

In our study, the dietary phosphorus levels tested did not significantly influence either dermal or endochondral acellular bone mineralization in turbot. These results are opposed to those found in haddock, a fish species with also an anosteocytic (acellular) bone, where dietary phosphorus significantly affected bone mineralization. It was found that juvenile haddock fed a diet containing a higher percentage of phosphorus (1.42\%) had higher bone mineralization, whereas juvenile haddock fed a diet containing lower phosphorus $(0.47 \%)$ had significantly lower bone mineral content (Roy \& Lall, 2003; Roy et al., 2002). Thus, the acellular bone metabolism remains still unclear. A possible explanation for the different responses between different acellularboned species could be related to specific species behaviour and traits. Fish species exhibiting active swimming or high swimming speeds maintain continuous stress and mechanical load on the skeleton, which is remodelled in response to regular damage 


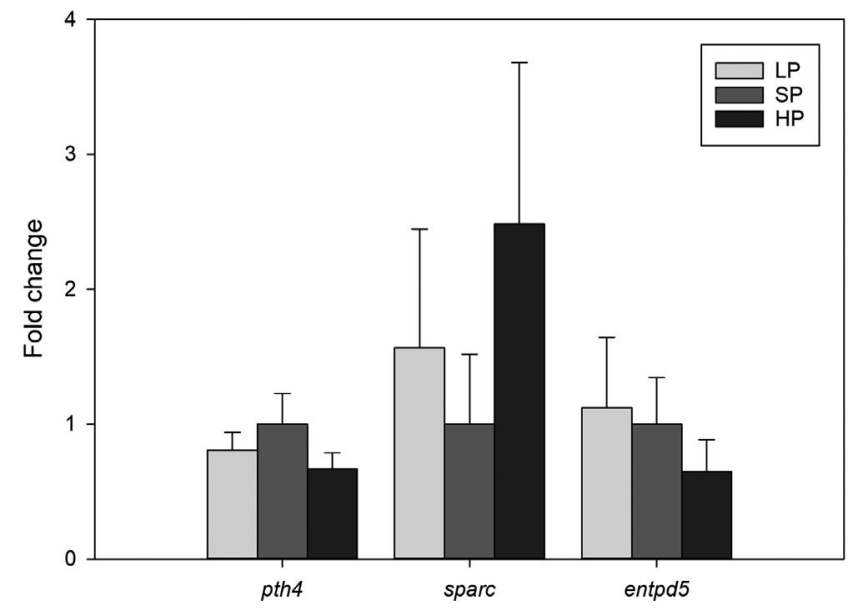

FIGURE 3 Quantitative RT-PCR gene expression analysis of bone mineral homeostasis markers (pth4, sparc and entpd5) in turbot fed HP, SP and LP diets. Results normalized to $18 \mathrm{~S}$ are expressed as mean \pm SEM. Data from the SP diet were set at 1 . The dietary treatments did not influence gene expression levels

(Atkins et al., 2014; Totland et al., 2011). Nevertheless, turbot are slow swimming fish since they are bottom dwellers, and therefore, bone is not expected to experience high loads. Another plausible explanation for these different responses could be related to the diet and the experimental protocols. In our experiment, the diets selected were maybe incompletely phosphorus deficient, and/or maybe 20 weeks was not sufficient time to show alterations. Additionally, however, what is evident is that the phosphorus requirements for optimum growth and bone mineralization in turbot are below those currently used commercially (i.e. the SP diet).

\section{5 | CONCLUSION}

In this study, we demonstrated that turbot, a demersal anosteocytic (acellular) boned fish species, require a lower dietary phosphorus concentration for optimum bone mineralization than those currently used commercially (i.e. the SP diet), at least for the time period examined: 55-195 dpf. Dietary phosphorus did not significantly influence bone mineral density in acellular turbot bone. Therefore, our results open a door to a possible differential regulation of phosphate homeostasis depending possibly on the type of bone and the specific behaviour and traits that a certain fish species has. Nevertheless, further studies with other acellular-boned fish species with different behaviour and traits should be carried out to explore how the skeletons of these animals perform the fundamental functions attributed to osteocytes in other vertebrates. Our results could additionally contribute to the design of a new feed formulation taking into account the type of bone and the particular behaviour and traits of each specific fish species, which ultimately will contribute to the balance between the requirements for optimal physiology, fast growth, and reduced environmental impact.

\section{ACKNOWLEDGEMENTS}

We would like to thank Rosa Cal, Castora Gómez and the staff of the Instituto Español de Oceanografía (IEO) for their help in handling and care of the fish. This work was funded by the Spanish Economy and Competitiveness Ministry project AGL2014-52473R and AGL2017-89648P to JR. PS-B was supported by AGL2014-52473R and AGL2017-89648P project contracts.

\section{ORCID}

Paula Suarez-Bregua (D) https://orcid.org/0000-0002-5303-1447

\section{REFERENCES}

Al-Maghazachi, S. J., \& Gibson, R. (1984). The developmental stages of larval turbot, Scophthalmus maximus (L.). Journal of Experimental Marine Biology and Ecology, 82, 35-51.

Atkins, A., Dean, M. N., Habegger, M. L., Motta, P. J., Ofer, L., Repp, F., Shahar, R. (2014). Remodeling in bone without osteocytes: Billfish challesnge bone structure-function paradigms. Proceedings of the National Academy of Sciences, 111(45), 16047-16052. https://doi. org/10.1073/pnas.1412372111

Baeverfjord, G., Asgard, T., \& Shearer, K. D. (1998). Development and detection of phosphorus deficiency in Atlantic salmon, Salmo salar L., parr and post-smolts. Aquaculture Nutrition, 4(1), 1-11. https:// doi.org/10.1046/j.1365-2095.1998.00095.x

Bonjour, J.-P. (2011). Calcium and phosphate: a duet of ions playing for bone health. Journal of the American College of Nutrition, 30(5 Suppl 1), 438S-488S.

Chaimongkol, A., \& Boonyaratpalin, M. (2001). Effects of ash and inorganic phosphorus in diets on growth and mineral composition of seabass Lates calcarifer (Bloch). Aquaculture Research, 32, 53-59. https://doi.org/10.1046/j.1355-557x.2001.00035_32_s1.x

Cho, C. Y., \& Bureau, D. P. (2001). A review of diet formulation strategies and feeding systems to reduce excretory and feed wastes in aquaculture. Aquaculture Research, 32(s1), 349-360. https://doi. org/10.1046/j.1355-557x.2001.00027.x

Correll, D. L. (1998). The role of phosphorus in the eutrophication of receiving waters: A review. Journal of Environment Quality, 27(2), 261266. https://doi.org/10.2134/jeq1998.00472425002700020004x

Costa, J., Sartori, M., Nascimento, N., Kadri, S., Ribolla, P., Pinhal, D., \& Pezzato, L. (2018). Inadequate dietary phosphorus levels cause skeletal anomalies and alter osteocalcin gene expression in zebrafish. International Journal of Molecular Sciences, 19(2), 364. https:// doi.org/10.3390/ijms19020364

Daneshgar, S., Callegari, A., Capodaglio, A., \& Vaccari, D. (2018). The potential phosphorus crisis: Resource conservation and possible escape technologies: a review. Resources, 7(2), 37. https://doi. org/10.3390/resources7020037

Dauda, A. B., Ajadi, A., Tola-Fabunmi, A. S., \& Akinwole, A. O. (2019). Waste production in aquaculture: Sources, components and managements in different culture systems. Aquaculture and Fisheries. Keai Communications Co. https://doi.org/10.1016/j. aaf.2018.10.002

Fjelldal, P. G., Hansen, T. J., Lock, E. J., Wargelius, A., Fraser, T. W. K., Sambraus, F., \& Ørnsrud, R. (2016). Increased dietary phosphorous prevents vertebral deformities in triploid Atlantic salmon (Salmo salar L.). Aquaculture Nutrition, 22(1), 72-90. https://doi. org/10.1111/anu.12238.

Hixson, S. M. (2014). Fish nutrition and current issues in aquaculture: The balance in providing safe and nutritious seafood, in an environmentally sustainable manner. Journal of Aquaculture Research \& Development, 3(3), 1-10. https://doi.org/10.4172/215 5-9546.1000234 
Huitema, L. F., Apschner, A., Logister, I., Spoorendonk, K. M., Bussmann J., Hammond, C. L., \& Schulte-Merker, S. (2012). Entpd5 is essential for skeletal mineralization and regulates phosphate homeostasis in zebrafish. Proceedings of the National Academy of Sciences, 109(52), 21372-21377. https://doi.org/10.1073/pnas.1214231110

Hur, M., Gistelinck, C. A., Huber, P., Lee,J., Thompson, M. H., MonstadRios, A. T., ... Kwon,R. Y. (2017). MicroCT-based phenomics in the zebrafish skeleton reveals virtues of deep phenotyping in a distributed organ system. eLife, 6, e26014. https://doi.org/10.7554/ eLife. 26014

Jahan, P. A., Watanabe, T. A., Satoh, S. H., \& Kiron, V. I. (2000). Effect of dietary fish meal levels on environmental phosphorus loading from carp culture. Fisheries Science, 66(2), 204-210. https://doi. org/10.1046/j.1444-2906.2000.00036.x

Kini, U., \& Nandeesh, B. N. (2012). Physiology of bone formation, remodeling, and metabolism. In I. Fogelman, G. Gnanasegaran, \& H. Wall (Eds.), Radionuclide and hybrid bone imaging (pp. 29-57). Springer. https://doi.org/10.1007/978-3-642-02400-9

Lall, S. P. (2002). The minerals. In J. E. Halver, \& R. W. Hardy (Eds.), Fish nutrition (pp. 259-308). Academic Press. https://doi.org/10.1016/ B978-012319652-1/50006-9

Lall, S. P., \& Lewis-McCrea, L. M. (2007). Role of nutrients in skeletal metabolism and pathology in fish - An overview. Aquaculture, 267(14), 3-19. https://doi.org/10.1016/j.aquaculture.2007.02.053

Lazzari, R., \& Baldisserotto, B. (2008). Nitrogen and phosphorus waste in fish farming. Boletim do Instituto De Pesca, 34(4), 591-600.

Le Luyer, J., Deschamps, M. H., Proulx, E., Poirier Stewart, N., Robert, C., \& Vandenberg, G. (2014). Responses of different body compartments to acute dietary phosphorus deficiency in juvenile triploid rainbow trout (Oncorhynchus mykiss, Walbaum). Journal of Applied Ichthyology, 30(4), 825-832. https://doi.org/10.1111/jai.12519

Lewis-McCrea, L. M., \& Lall, S. P. (2010). Effects of phosphorus and vitamin $C$ deficiency, vitamin A toxicity, and lipid peroxidation on skeletal abnormalities in Atlantic halibut (Hippoglossus hippoglossus). Journal of Applied Ichthyology, 26(2), 334-343. https://doi. org/10.1111/j.1439-0426.2010.01431.x

Li, N., Felber, K., Elks, P., Croucher, P., \& Roehl, H. H. (2009). Tracking gene expression during zebrafish osteoblast differentiation. Developmental Dynamics, 238(2), 459-466. https://doi.org/10.1002/dvdy.21838

Luo, Z., Li, X., Gong, S., Xi, W., \& Li, Y. (2009). Effect of dietary phosphorus on the growth and body components of juvenile Synechogobius hasta. Journal of Ocean University of China, 8(1), 65-70. https://doi. org/10.1007/s11802-009-0065-1

Mallekh, R., Boujard, T., \& Lagardère, J. P. (1999). Evaluation of retention and environmental discharge of nitrogen and phosphorus by farmed Turbot (Scophthalmus maximus). North American Journal of Aquaculture, 61(2), 141-145. https://doi.org/10.1577/15488454(1999)061<0141:EORAED>2.0.CO;2

Ogino, C., \& Takeda, H. (1976). Mineral requirements in fish III. Calcium and phosphorus requirements in carp. Bulletin of the Japanese Society of Scientific Fisheries, 42(7), 793-799. https://doi. org/10.2331/suisan.42.793

Pfaffl, M. W. (2001). A new mathematical model for relative quantification in real-time RT-PCR. Nucleic Acids Research, 29(9), 2002-2007. https://doi.org/10.1093/nar/29.9.e45

Roy, P. K., \& Lall, S. P. (2003). Dietary phosphorus requirement of juvenile haddock (Melanogrammus aeglefinus L.). Aquaculture, 221(1-4), 451468. https://doi.org/10.1016/S0044-8486(03)00065-6

Roy, P. K., Witten, P. E., Hall, B. K., \& Lall, S. P. (2002). Effects of dietary phosphorus on bone growth and mineralisation of vertebrae in haddock (Melanogrammus aeglefinus L.). Fish Physiology and Biochemistry, 27(1/2), 35-48. https://doi.org/10.1023/ B:FISH.0000021778.99011.ce

Shahar, R., \& Dean, M. N. (2013). The enigmas of bone without osteocytes. BoneKEy Reports, 2, 1-8. https://doi.org/10.1038/bonek ey.2013.77

Sims, N. A., \& Gooi, J. H. (2008). Bone remodeling: multiple cellular interactions required for coupling of bone formation and resorption. Seminars in Cell \& Developmental Biology, 19(5), 444-451. https:// doi.org/10.1016/j.semcdb.2008.07.016

Suarez-Bregua, P., Torres-Nunez, E., Saxena, A., Guerreiro, P., Braasch, I., Prober, D. A., Rotllant, J. (2017). Pth4, an ancient parathyroid hormone lost in eutherian mammals, reveals a new brain-to-bone signaling pathway. The FASEB Journal, 31(2), 569-583. https://doi. org/10.1096/fj.201600815R

Sugiura, S. H., Gabaudan, J., Dong, F. M., \& Hardy, R. W. (2001). Dietary microbial phytase supplementation and the utilization of phosphorus, trace minerals and protein by rainbow trout [Oncorhynchus mykiss (Walbaum)] fed soybean mealbased diets. Aquaculture Research, 32(7), 583-592. https://doi. org/10.1046/j.1365-2109.2001.00581.x

Sugiura, S. H., Hardy, R. W., \& Roberts, R. J. (2004). The pathology of phosphorus deficiency in fish - a review. Journal of Fish Diseases, 27(5), 255-265. https://doi.org/10.1111/j.1365-2761.2004.00527.x

Torres-Núñez, E., Suarez-Bregua, P., Cal, L., Cal, R., Cerdá-Reverter, J. M., \& Rotllant, J. (2015). Molecular cloning and characterization of the matricellular protein Sparc/osteonectin in flatfish, Scophthalmus maximus, and its developmental stage-dependent transcriptional regulation during metamorphosis. Gene, 568(2), 129-139. https:// doi.org/10.1016/j.gene.2015.05.036

Totland, G. K., Fjelldal, P. G., Kryvi, H., Løkka, G., Wargelius, A., Sagstad, A., Hansen, T., \& Grotmol, S. (2011). Sustained swimming increases the mineral content and osteocyte density of salmon vertebral bone. Journal of Anatomy, 219(4), 490-501. https://doi. org/10.1111/j.1469-7580.2011.01399.x

Vielma, J., \& Lall, S. P. (1998). Control of phosphorus homeostasis of Atlantic salmon (Salmo salar) in fresh water. Fish Physiology and Biochemistry, 19(1), 83-93. https://doi.org/10.1023/A:10077 57321695

Witten, P. E., \& Huysseune, A. (2009). A comparative view on mechanisms and functions of skeletal remodelling in teleost fish, with special emphasis on osteoclasts and their function. Biological Reviews of the Cambridge Philosophical Society, 84(2), 315-346. https://doi. org/10.1111/j.1469-185X.2009.00077.x

Witten, P. E., Owen, M. A. G., Fontanillas, R., Soenens, M., Mcgurk, C., \& Obach, A. (2016). A primary phosphorus-deficient skeletal phenotype in juvenile Atlantic salmon Salmo salar: The uncoupling of bone formation and mineralization. Journal of Fish Biology, 88(2), 690-708. https://doi.org/10.1111/jfb.12870

How to cite this article: Suarez-Bregua P, Pirraco RP, Hernández-Urcera J, Reis RL, Rotllant J. Impact of dietary phosphorus on turbot bone mineral density and content. Aquacult Nutr. 2021;00:1-7. https://doi.org/10.1111/ $\underline{\text { anu. } 13253}$ 